MAÑALICH, Juan Pablo, “Recensión: GUZMÁN DÁLBORA, José Luis,

Figuras y pensamientos del Derecho penal contemporáneo.

Montevideo y Buenos Aires: Editorial BdF, 2014, xiv + 250 páginas."

Polít. crim. Vol. 10, № 19 (Julio 2015), Rec. 2, pp. 398 - 408.

[http://www.politicacriminal.cl/Vol_10/n_19/Vol10N19R2.pdf]

\title{
Una defensa (¿intempestiva?) de la dogmática jurídico-penal como proyecto histórico*
}

\author{
Recensión: GUZMÁN DALBORA, José Luis, Figuras y pensamientos del Derecho \\ penal contemporáneo. \\ Montevideo y Buenos Aires, Editorial BdF, 2014, xiv + 250 páginas.
}

\section{An (untimely?) defense of the juridical-legal dogmatic as a historical project}

\section{Review: GUZMÁN DALBORA, José Luis, Figuras y pensamientos del Derecho penal contemporáneo (Icons and thoughts of contemporary Penal law) \\ Montevideo and Buenos Aires, Editorial BdF, 2014, xiv +250 pages. \\ Dr. Juan Pablo Mañalich R. \\ Profesor asociado del Departamento de Ciencias Penales, Universidad de Chile ipmanalich@derecho.uchile.cl}

El libro cuya publicación celebramos es, ante todo, un libro improbable. Esta sola consideración basta para estar inmensamente agradecido por la generosa distinción que su autor, el Prof. José Luis Guzmán Dalbora, me ha brindado al invitarme a presentarlo. Pues en una época en la cual la producción bibliográfica en el ámbito de nuestra disciplina ha alcanzado un nivel bastante próximo al de una auténtica vorágine, el volumen Figuras y pensamientos del Derecho penal contemporáneo nos interpela en la forma de un afable a la vez que severo recordatorio de que los argumentos y problemas de los cuales los penalistas nos ocupamos y nos volvemos a ocupar, con una insistencia que en algunos momentos puede llegar a parecer frenética, han ido quedando definidos en un arco histórico cuyo desconocimiento nos deja enfrentados al riesgo de creer $-\mathrm{y}$ más gravemente aún: de pretender hacer creer a otros- que con cada artículo y monografía que publicamos tendríamos que quedar próximos a reinventar la rueda sobre la que gira, recursivamente, aquello que Guzmán Dalbora llama la "atroz disciplina".

En tal medida, pienso que el libro se deja interpretar -lo sepa o no su autor; soy un acérrimo objetivista en cuestiones de interpretación- como un homenaje a una cierta actitud intelectual, que yo identificaría con la resistencia frente al pathos de la originalidad que parece gobernar nuestros empeños académicos. En efecto, parecería que el parámetro determinante para enjuiciar la relevancia y la pertinencia de las jugadas que ensayamos sobre el tablero de ajedrez de la dogmática jurídico-penal está constituido por su pretendida novedad; esto lo sabe quien quiera que esté sometido al constreñimiento burocrático de publicar regularmente en nuestras sacrosantas "revistas indexadas".

\footnotetext{
* El presente trabajo se corresponde con una versión levemente revisada complementada del texto leído con ocasión de la presentación del libro de referencia, celebrada el día jueves 13 de noviembre de 2014, en la Facultad de Derecho de la Universidad de Valparaíso.
} 


\section{MAÑAICH, Juan Pablo, “Recensión: GUZMÁN DÁLBORA, José Luis, Figuras y pensamientos del Derecho penal contemporáneo. Montevideo y Buenos Aires: Editorial BdF, 2014, xiv + 250 páginas.”}

En este contexto, el libro de Guzmán Dalbora puede ser leído como una contribución terapéutica, justamente porque nos recuerda que este juego se viene jugando hace ya mucho tiempo, y por jugadores tanto más eximios que nosotros, en términos tales que cualquier pretensión de genuina innovación que podamos abrazar en el presente corre el riesgo cierto de develarse, más bien, como expresiva de un posible déficit bibliográfico.

La cientificidad de la dogmática depende, críticamente, de que ella sea cultivada con consciencia histórica. Desde este preciso punto de vista, la contribución de Guzmán Dalbora resulta ser simplemente insoslayable para los lectores de habla hispana. Pues los ocho trabajos reunidos en el volumen se corresponden con los estudios introductorios que nuestro autor preparara para la publicación de las traducciones de sendas monografías que llegaran a hacer época en la literatura alemana, traducciones todas acometidas, con el mayor de los éxitos, por el propio Guzmán Dalbora. Y si esta labor de traducción por sí sola resulta ya de inestimable valía, el hecho de que cada una de ellas nos haya sido obsequiada en la compañía de un profundo y erudito estudio preliminar por parte de su traductor revela no solo una inusitada generosidad, sino al mismo tiempo un profundo respeto por la trayectoria intelectual de cada uno de los ocho juristas que nos legaran las obras así introducidas. Es precisamente esto lo que, de modo enteramente exacto, se nos anuncia ya desde el mismo título del libro: su lectura nos lleva a comprobar la medida en que en la generación de una obra intelectual se ven reflejadas las circunstancias biográficas de su autor. O para ponerlo en las palabras del propio Guzmán Dalbora, plasmadas en su prefacio al libro: "Sus figuras corren parejas a los pensamientos respectivos, porque toda tesis científica tiene un autor, es fruto de un ser creador y, en consecuencia, no es factible separarla totalmente de quien la gestó" (p. xii).

Sin que el libro lo haga explícito -sospecho que la elegancia y modestia de nuestro colega y amigo haría tal declaración del todo imposible-, el mismo nos sugiere que ello también vale para $s u$ autor. Pues el temperamento teórico y político de Guzmán Dalbora parece asomarse en la selección misma de los ocho trabajos por él traducidos y presentados, así como por su reseña de la personalidad de cada uno de sus autores. Es indiscutible que los autores de los ocho trabajos cuyos estudios introductorios constituyen el libro que comentamos se ven unidos por una vocación antaño representativa del fuste de un auténtico jurista, pero hoy cada vez más infrecuente, a saber: la vocación por el cultivo simultáneo, y más importantemente aún: integrado, de la dogmática jurídica y la filosofía del derecho. Y es precisamente esta vocación, que en nuestros días muestra un franco declive, lo que hace de Guzmán Dalbora -si se me permite la expresión- una auténtica rara avis en el panorama de nuestra fauna científica. Y aunque está de más decirlo: enhorabuena.

Pero si lo anterior es indicativo de un marcadísimo rasgo de su temperamento teórico, en esa selección de obras y biografías, de pensamientos y figuras, también se muestra, como ya lo anticipaba, el temperamento político de nuestro autor: entre los ocho juristas en el estudio de cuya obra y vida Guzmán Dalbora ha invertido tiempo y talento, cinco de ellos son retratados, por el propio Guzmán, como inequívocamente proclives a alguna u otra expresión del liberalismo, a saber: Birbaum y Jhering, a quienes muestro autor identifica como favorecedores de un "liberalismo conservador"; Mayer, cuyo "relativismo crítico" lo 
Polít. crim. Vol. 10, Nº 19 (Julio 2015), Rec. 2, pp. 398 - 408.

[http://www.politicacriminal.cl/Vol_10/n_19/Vol10N19R2.pdf]

mostraría indudablemente comprometido con "el programa político del liberalismo"; Maihofer, a propósito de cuya militancia en el Partido Demócrata Liberal alemán Guzmán Dalbora da cuenta del reconocimiento de que gozara como "teórico del liberalismo de izquierda"; y -last but not least- Radbruch, quien con razón nos es presentado como sustentador de "la doctrina política liberal y la teoría económica socialista".

De los tres autores restantes, hay buenas razones para asumir que Freudenthal también se deja incluir en el grupo de los partidarios de alguna versión de auténtico liberalismo político. Indicios de ello se encuentran, me parece, en la reseña que Guzmán Dalbora hace de su producción bibliográfica, la cual se muestra determinada por una clara preocupación por la situación jurídica del preso y en general por la legalidad de los regímenes de ejecución penal, banderas éstas que han tendido a ser levantadas por penalistas ideológicamente comprometidos con el liberalismo.

El asunto se pone peliagudo, empero, en lo concerniente a las dos figuras restantes: Heinrich Henkel y Karl Engisch. Respecto del primero, quien entre otras cosas destaca por ser el maestro de Claus Roxin, Guzmán Dalbora nos informa de su militancia -activa- en el partido nacionalsocialista, a partir del año 1933, no sin antes constatar las dificultades enfrentadas en la obtención de antecedentes biográficos de Henkel, "a propósito de quien las fuentes al uso para estos casos son extremadamente pobres" (p. 155, n. 20). A este respecto, me atrevería a complementar la observación de Guzmán Dalbora, en el sentido de que no es en absoluto casualidad que, tratándose de un jurista afiliado al nazismo, dispongamos de pocas fuentes de información en lo tocante al curso de su vida. Me permito formular esta disquisición, para así intentar construir una eximente - $\mathrm{o}$ en todo caso una atenuante muy calificada- a favor de nuestro autor, quien en su reseña de Engisch omite mencionar su respectiva filiación al nacionalismo ${ }^{1}$.

Digo que lo que así pretendo es remover la base para un posible reproche por esta omisión, porque en el caso de Engisch la falta de antecedentes disponibles es todavía más llamativa, no sólo por tratarse de uno de los teóricos alemanes del derecho penal más importantes de todo el siglo XX, sino también porque ni siquiera en el libro homenaje que le fuera dedicado con ocasión de su septuagésimo cumpleaños figura una semblanza biográfica de su persona ${ }^{2}$. Ciertamente, esta omisión no impide a Guzmán Dalbora dar cuenta de la comodidad con la cual Engisch pudo desempeñarse como académico universitario una vez producida la Machtergreifung por parte de Hitler y los suyos, "sin tener que resignar su dignidad personal al nuevo régimen", observando con justicia que del "clima ponzoñoso

\footnotetext{
${ }^{1}$ Véase REMY, Steven, The Heidelberg Myth: The Nazification and Denazification of a German University, Boston: Harvard University Press, 2002, pp. 138, 158, quien sostiene que Engisch habría dado inicio a su militancia en el NSPD en el año 1937. Del proceso de "desnazificación" al cual Engisch hubo de someterse al cabo de la guerra, junto a otros académicos de la Universidad de Heidelberg, informa la propia página web de esta institución, en el siguiente link: http://www.jura.uni-heidelberg.de/fakultaet/fakultaetsgeschichte.html. Para una revisión histórica de la situación de la Universidad de Heidelberg durante los años de la dominación nacionalsocialista, con múltiples referencias a la persona y el desempeño de Karl Engisch, véase EUCKART, Wolfgang, SELLIN, Volker y WOLGAST, Eike, Die Universität Heidelberg im Nationalsozialismus, Heidelberg: Springer, 2006.

${ }^{2}$ Véase BOCKELMANN, Paul, KAUFMANN, Arthur y KLUG, Ulrich, Festschrift für Karl Engisch zum 70. Geburtstag, Fráncfort del Meno: Vittorio Klostermann, 1969.
} 


\section{MAÑALICH, Juan Pablo, “Recensión: GUZMÁN DÁLBORA, José Luis, Figuras y pensamientos del Derecho penal contemporáneo. Montevideo y Buenos Aires: Editorial BdF, 2014, xiv + 250 páginas.”}

que se enseñoreó del país, siquiera nadie y mucho menos un joven profesor, estaba en posición de sustraerse del todo a tamaña prepotencia" (p. $206 \mathrm{~s}$ ).

El punto me parece importante, por dos razones. En primer lugar, porque hace posible que nos formemos una impresión de cómo puede llegar a transcurrir, plácida y exitosamente, la vida de un talento intelectual de difícil parangón durante la instalación y el desarrollo de un régimen de dominación totalitaria. Pero en segundo lugar, el punto tiene significación porque nos muestra que, por más execrable que haya sido el posicionamiento ideológico o político de un intelectual, ello jamás debería nublarnos el juico a la hora de apreciar el mérito de su contribución a nuestro entendimiento de la correspondiente parcela del mundo. Sin histeria y adultamente, lo que corresponde en tal caso es asumir la desazón, y quizá el desconcierto. Guardando las proporciones, ésta es la actitud que ponía de manifiesto el filósofo británico Michael Dummett, cuando cerraba el prefacio de su fundamental monografía dedicada a la filosofía del lenguaje del fundador de la lógica matemática moderna, el alemán Gottlob Frege. Me permito citar a Dummett in extenso:

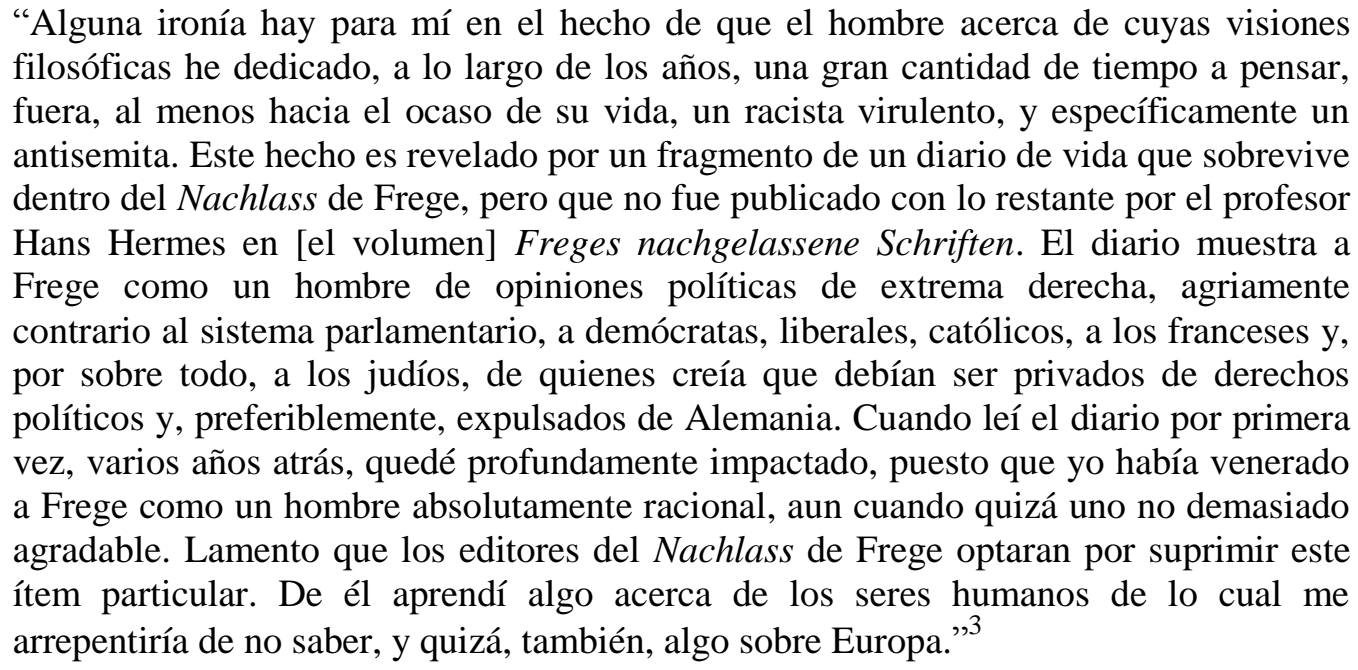

Y entonces vuelvo al punto: el hecho de que Guzmán Dalbora reseñe la vida y la trayectoria intelectual de dos juristas que indudablemente se adaptaron, con docilidad, a las condiciones de dominación impuestas por un régimen que ab initio mostraba su radical repulsa de toda forma de democracia y un programa de acción explícitamente racista, dando cuenta de la magnitud de su respectiva contribución a la "atroz disciplina", ejemplifica una específica virtud que trasunta el volumen en su conjunto, a saber: una irrestricta honestidad científica.

Lo anterior deja intacto, por supuesto, que a lo largo de las páginas que lo componen el libro de Guzmán Dalbora nos vaya dejando entrever dónde se hallan puestas las predilecciones teóricas de su autor. Nuevamente, el primer dato básico con el que nos confrontamos proviene de la nómina misma de los juristas cuyas posiciones doctrinales son analizadas y contextualizadas de un capítulo a otro. Con las excepciones de Birnbaum y

\footnotetext{
${ }^{3}$ DUMMETT, Michael, Frege. Philosophy of Language, Nueva York: Harper \& Row, 1973, p. xii.
} 
Polít. crim. Vol. 10, No 19 (Julio 2015), Rec. 2, pp. $398-408$.

[http://www.politicacriminal.cl/Vol_10/n_19/Vol10N19R2.pdf]

Jhering, los protagonistas intelectuales del libro se dejan adscribir, sin mayores contorsiones, a la órbita del neokantismo, cuya expresión en la dogmática del derecho penal no se deja entender si se prescinde, empero, de las aportaciones que nos legaran Birbaum y Jhering. Ello provee al volumen -si se quiere: subterráneamente- de un Leitmotiv unificador, consistente en la descripción y evaluación, aun cuando inevitablemente discontinua y fragmentada, de la trayectoria histórica de ese esquema de teorización, fundamentalmente determinado por un dualismo metodológico que lleva a diferenciar sistemáticamente los dominios de lo empírico y lo normativo como dimensiones heterogéneas de nuestro modo de existencia. Para un lector cuyas inclinaciones filosóficas están más bien situadas en las antípodas de toda forma de dualismo, sea metafísico, sea epistemológico, el volumen de Guzmán Dalbora se ofrece como una invitación a comprobar el progreso científico susceptible de ser reconocido en el despliegue de poderosísima tradición de pensamiento, cuyo estatus de tal no se ve en un ápice mermado por la posible insolvencia de algunas de sus premisas filosóficas.

En lo que sigue, quisiera proceder selectivamente, apenas adentrándome en algunos de los problemas que se ven muy sólidamente reconstruidos en los que a mi juicio son los tres capítulos más logrados del libro, a saber: los referidos a Jhering y el surgimiento de una concepción objetivista del injusto; a Mayer y su teoría de las normas de la cultura; y a Engisch y su tratamiento del problema de la libertad y el determinismo.

En lo concerniente al así llamado "descubrimiento" de la objetividad de la antijuridicidad por parte de Jhering, Guzmán Dalbora logra, en unas pocas pero muy eficaces páginas, ilustrar cómo el meollo de la disputa que el romanista y civilista Jhering mantuviera con el criminalista Adolf Merkel se refería menos a la naturaleza objetiva o subjetiva de la ilicitud como tal, sino más bien a la pregunta por la unidad o diversidad de todas las posibles instancias de antijuridicidad. Pues recuérdese que a Jhering interesaba demostrar la necesidad de que, en el derecho privado, la ilicitud de un hecho pudiera ser íntegramente disociada de la culpabilidad por ese hecho ilícito, sin que ello afectara que el injusto con relevancia para el derecho penal sólo podría constituirse como un injusto culpable, proposición ésta sustentada tanto por Jhering como por Merkel. Sobre esta base, Guzmán Dalbora logra sugerir que el genuino eje del dilema se halla en grado sumo determinado por el problema normológico representado por el influjo del imperativismo, respecto de lo cual nuestro autor acertadamente concluye, desafiando el lugar común en el cual ha devenido lo que hoy día se conoce, en retrospectiva, como el "problema del destinatario", que una conceptualización imperativista de las normas no es incompatible con una comprensión puramente objetivista de la ilicitud.

En el mismo contexto, Guzmán Dalbora oportunamente menciona -en una nota al pie de página- a Johannes Nagler como uno de los más reconocidos suscriptores de la tesis según la cual la antinormatividad de un comportamiento, entendida como su propiedad consistente en ser contrario a la norma respectiva, se deja conceptuar como una propiedad enteramente objetiva. Esto resulta de interés, porque Nagler, el más importante de los discípulos de Binding, sugirió ésta como la única rectificación necesaria en la defensa del 


\section{MAÑALICH, Juan Pablo, "Recensión: GUZMÁN DÁLBORA, José Luis, \\ Figuras y pensamientos del Derecho penal contemporáneo. \\ Montevideo y Buenos Aires: Editorial BdF, 2014, xiv + 250 páginas."}

monumental programa teórico de su maestro ${ }^{4}$, dado que Binding, tomando parte en el debate abierto por Jhering y Merkel, efectivamente había sostenido, con su vigor característico, que la noción de un injusto no culpable era, desde el punto de vista específicamente jurídico-penal, una aberración del pensamiento ${ }^{5}$. Según Binding, la premisa para ello quedaba ya determinada por el hecho de que una norma cuyo quebrantamiento pudiera ser constitutivo de la respectiva instancia de injusto merecedora de pena efectivamente tenía que ser pensada como un imperativo, y más precisamente: como una orden (Befehl) emitida, expresa o concluyentemente, por el Estado.

Es justamente en pos de la refutación del modelo de teoría de las normas de Binding en atención a este último aspecto -a saber: el del estatus de la norma quebrantada por el autor del respectivo hecho punible qua norma jurídica estatalmente producida- que Max Ernst Mayer elaboró su célebre teoría de las normas de la cultura, que Guzmán Dalbora presenta y defiende en el tercer capítulo del libro. Si bien nuestro autor da cuenta de que, en su polémica con Mayer, Binding se habría mostrado en último término "atrapado en las redes del conceptualismo al que pertenecía" (p. 79), algunas líneas más abajo identifica el quid de la discrepancia en el compromiso bindingiano con una comprensión de la relación entre el Estado y el destinatario de la norma puesta en vigor por aquél como una relación vertical de subordinación. Me parece, sin embargo, que en este pasaje Guzmán Dalbora tiende tal vez a mantener en exceso vinculadas la objeción, de índole más bien metodológica, en contra del cultivo, por parte de Binding, de la vieja y buena jurisprudencia de conceptos, por una parte, y la objeción propiamente ideológica que apunta a la dependencia de la teoría de las normas de Binding respecto de un modelo de positivismo estatista, por otra. Mas puede ser crucial mantener separadas las dos objeciones, para así preservar la arquitectura del edificio teórico que nos legara Binding, cuyo mérito radica en su excepcional rigor analítico, purgándolo de su compromiso con una concepción autoritariamente estatista de la producción e identificación del derecho.

En contra de la propuesta de Mayer, sin embargo, semejante purga del modelo normológico de Binding no necesita pasar por la negación del carácter propiamente jurídico de las normas cuyo quebrantamiento puede resultar delictivo, y punible. Pues el precio a pagar por semejante maniobra teórica está lejos de ser exiguo: ¿en qué sentido cabe identificar el injusto con relevancia jurídico-penal con una instancia de quebrantamiento del derecho si la norma de cuyo quebrantamiento se trata carece de estatus jurídico? A este respecto, es posible que el propio Mayer haya enfatizando excesivamente los términos de su discrepancia con Binding. Pues si, tal como ello es debidamente documentado por nuestro autor, Mayer ciertamente admite que, para que su quebrantamiento imputable pueda fungir como objeto de un reproche jurídico de culpabilidad, la respectiva norma de la cultura habrá de haber sido legislativamente reconocida por el Estado, cabría sugerir que la correcta reconstrucción del debate tendría que redefinirlo no como una controversia acerca

\footnotetext{
${ }^{4}$ NAGLER, Johannes, "Der heutige Stand der Lehre von der Rechtswidrigkeit", en: BELING, Ernst et al., Festschrift für Karl Binding zum 4. Juni 1911, Léipzig: Wilhelm Engelmann, 1911, tomo II, pp. 273 ss., 331 ss., $367 \mathrm{~s}$.

${ }^{5}$ Véase BINDING, Karl, Die Normen und ihre Übertretung, tomo I, 4ª ed., Léipzig: Felix Meixner, 1922, pp. 270 ss., 298 ss.
} 
del estatus -jurídico o cultural- de las normas punitivamente reforzadas, sino más bien como una controversia acerca del concepto mismo de validez jurídica.

Me permito solamente insinuar la vía por la cual podría, quizá, encaminarse la solución del problema, a saber: irónicamente, a través de una teoría de la validez jurídica que explique cómo el reconocimiento legislativo de una determinada norma depende, a su vez, de que la eficacia normativa del ejercicio de semejante potestad legislativa se encuentre a su vez reconocida, en último término, por el grupo social cuyos miembros están expuestos a ser hechos llamados a responder por el quebrantamiento de tal norma. Ese es el proyecto de las teorías de la validez conocidas como teorías del reconocimiento, cuyo exponente más preclaro, Ernst Rudolf Bierling ${ }^{6}$, comparte un lugar honorífico con Mayer, al haber sido, al igual que éste, duramente fustigado por ese brillante enfant terrible del neokantismo cuyo apellido es Kelsen ${ }^{7}$. Para rescatar el auténtico núcleo de verdad de la teoría de las normas de la cultura de Mayer, quizá sea imprescindible revisitar la teoría general de la validez jurídica, pero justamente liberando a ésta del dualismo del "ser" y el "deber-ser".

Si la teoría de las normas y su significación para la determinación del concepto de injusto ocupa varios notables pasajes del libro de Guzmán Dalbora, el mismo sitial corresponde a las disquisiciones sobre el sustento último de la culpabilidad por el injusto. A este respecto, el volumen nos ofrece un muy sugerente contraste de algunos hitos capitales en el desarrollo de lo que hoy conocemos como una concepción normativa de la culpabilidad, herencia perenne del neokantismo, por un lado, y una de las propuestas más potencialmente demoledoras de los basamentos de esa misma concepción, por otro. Como protagonistas de la historia de la edificación de la concepción normativa de la culpabilidad, el libro se ocupa de las contribuciones de Freudenthal y Henkel; en lo tocante a la eventual impugnación de sus fundamentos, Guzmán Dalbora nos entrega una muy lúcida revisión de la concepción de una culpabilidad por el carácter que Engisch articulara en su capital estudio del año 1963.

Quisiera enfatizar que estoy sugiriendo que en lo que Guzmán Dalbora identifica como "la fase destructiva" del desarrollo de la monografía de Engisch, a saber, su argumento a favor de la imposibilidad de una demostración del así llamado "libre albedrío", hallamos nada más que una eventual impugnación de los fundamentos de la concepción normativa de la culpabilidad. Con esto quiero decir que no es necesariamente el caso que el argumento de Engisch prive de sustento a una comprensión de la culpabilidad como reprochabilidad; que lo haga o no depende, críticamente, de si en efecto semejante comprensión de la culpabilidad tiene como premisa un compromiso con el indeterminismo. Y mi impresión es que ese supuesto compromiso sólo se vuelve indesmentible a partir de la apropiación de la concepción normativa de la culpabilidad por parte del finalismo, precisamente por la interpretación ontológica que Welzel hace de la así llamada "posibilidad de actuar de otro modo", en tanto fundamento de la culpabilidad qua reprochabilidad, en el sentido de una

\footnotetext{
${ }^{6}$ BIERLING, Ernst Rudolf, Zur Kritik der juristischen Grundbegriffe, Gotha: Friedrich Andreas Berthes, 1887 y 1883, pp. 68 ss., 81 ss., 351 ss.; también BIERLING, Ernst Rudolf, Juristische Prinzipienlehre, tomo I, J.C.B. Friburgo y Léipzig: Mohr (Paul Siebeck), 1894, pp. 19 ss., 40 ss.

${ }^{7}$ Véase KELSEN, Hans, Hauptprobleme der Staatsrechtslehre, Friburgo y Léipzig: J.C.B. Mohr (Paul Siebeck), 1911, pp. 346 ss., 369 ss.
} 


\section{MAÑALICH, Juan Pablo, "Recensión: GUZMÁN DÁLBORA, José Luis, \\ Figuras y pensamientos del Derecho penal contemporáneo. \\ Montevideo y Buenos Aires: Editorial BdF, 2014, xiv + 250 páginas.”}

estructura lógico-objetiva ${ }^{8}$. En cambio, una fundamentación propiamente normativa de la concepción normativa de la culpabilidad -valga, como nunca, la redundancia-, que fue la favorecida por los penalistas adscritos al neokantismo, tal como Guzmán Dalbora lo constata a propósito del punto de vista mantenido por Mayer, quizá pueda convivir, pienso, con la sospecha de que, como tesis acerca del estatus ontológico del comportamiento de los agentes humanos, el indeterminismo pudiera carecer de todo sustento.

Es justamente el propósito de conciliar la aceptabilidad de un juicio de reproche por la ejecución o la omisión de una determinada acción con la hipótesis de corroboración del carácter determinado del comportamiento humano, que Guzmán Dalbora acertadamente detecta y reconstruye en la monografía de Engisch, lo que convierte a éste en un preclaro partidario de lo que el debate filosófico más reciente conoce como una posición compatibilista, a saber, una posición que proclama la compatibilidad entre determinismo y autonomía agencial ${ }^{9}$. Es desde este punto de vista que la indagación de nuestro autor en la concepción de la culpabilidad sustentada por Engisch se vuelve de la mayor relevancia de cara al estado actual de la discusión sobre la fundamentación de la culpabilidad jurídicopenal, justamente porque en nuestros días la recepción de determinados hallazgos experimentales obtenidos de la así llamada "neuro-ciencia" parecen estar inclinando nuevamente la balanza de la penalística hacia el polo favorable al determinismo.

En la "fase constructiva" de su argumento, Engisch aboga por un modelo de culpabilidad por el carácter. Mas a este respecto, sólo parece producente acompañar a Guzmán Dalbora en su denuncia de que semejante modelo es efectivamente irreconciliable con la manera en que el principio de culpabilidad exige identificar los presupuestos del merecimiento de un reproche jurídico, y no ético, susceptible de verse materializado en la pena impuesta sobre una persona ("natural") ${ }^{10}$. Ello no obsta, sin embargo, a que tengamos que reconocer a Engisch el mérito indesmentible de haber puesto de manifiesto, aun cuando de manera equívoca, que la apelación al carácter de una persona resulta irrenunciable en la sustentación última del reproche de culpabilidad (por el hecho) susceptible de serle dirigido.

Puesto a modo de eslogan: el error capital de Engisch, pienso, consiste en haber confundido la posición que ha de ocupar la referencia al carácter ante la distinción entre el objeto y el sustrato del reproche de culpabilidad. Lo cual quiere decir: a diferencia de lo sostenido por Engisch, el carácter no ha de fungir como el objeto de un reproche de culpabilidad jurídicopenal, sino como el sustrato sobre el cual adquiere sentido el correspondiente reproche de culpabilidad por lo que el agente ha hecho o dejado de hacer. Y este preciso punto de vista

\footnotetext{
${ }^{8}$ WELZEL, Hans, Das deutsche Strafrecht, 10ª ed., Berlín: Walter de Gruyter, 1967, pp. 133 ss., 136 ss.

${ }^{9}$ Véase MAÑALICH, Juan Pablo, “Autonomía, determinismo y responsabilidad penal”, en: KINDHÄUSER, Urs y MAÑALICH, Juan Pablo, Pena y culpabilidad en el Estado democrático de derecho, Buenos Aires y Montevideo: BdF, pp. 181 ss., 190 ss.

${ }^{10}$ Aquí no corresponde entrar en la cuestión de si lo mismo vale para la fundamentación de la posible culpabilidad de una persona jurídica; a favor de la reconstrucción de la regulación plasmada en la Ley 20.353 a través de un modelo de culpabilidad por el carácter, véase MAÑALICH, Juan Pablo, "Organización delictiva. Bases para su elaboración dogmática en el derecho penal chileno", Revista Chilena de Derecho, vol. 38, No 2 (2011), pp. 279 ss., 296 ss., 302 ss.
} 
Polít. crim. Vol. 10, Nº 19 (Julio 2015), Rec. 2, pp. 398 - 408.

[http://www.politicacriminal.cl/Vol_10/n_19/Vol10N19R2.pdf]

se encuentra muy exactamente plasmado en una monografía publicada cincuenta y cinco años antes que el estudio de Engisch, cuyo autor es un dogmático en cuya suprema admiración -me consta- Guzmán Dalbora y yo coincidimos cabalmente: Ernst Beling.

En efecto, en su monografía del año 1908, que propone una muy sofisticada defensa de un modelo retribucionista de derecho penal, Beling se declara partidario de lo que él mismo caracteriza como un "indeterminismo condicionado". Lo notable, sin embargo, es que su presentación de esta tesis resulta enteramente congruente, más bien, con lo que hoy calificaríamos como una posición propiamente compatibilista, en el sentido ya explicado. Así, y en referencia a la posibilidad de dar cuenta de la capacidad de motivación autónoma de un agente que habita un mundo gobernado por "la ley de la causalidad", Beling observa

"que precisamente esa fuerza de resistencia, esa capacidad de elección o decisión, puede y en mi opinión tiene que ser ella misma pensada como un producto de causas, de modo tal que cada decisión adoptada, como sea que resulte, está conectada con las circunstancias antecedentes a través de una ligazón causal. La "libertad" ciertamente no necesita ser una libertad frente a la ley de causalidad. Si ella misma es causada y genera consecuencias causales, ¿no sigue siendo [...] por un lado "libertad" frente a aquellas fuerzas que concurren junto a ella queriendo co-condicionar la acción como producto, sin por otro lado caer fuera del suceso causal? [El alma humana ...], con ella la fuerza de resistencia, el poder esto o lo otro, se vuelve causal y así se conecta con el todo; y los productos de su poder, como sea que resulten, por su parte desembocan de vuelta en el suceso causal." 12

Esta imbricación de la libertad de voluntad en la estructura causal del mundo había sido ya célebremente formulada por Adolf Merkel: "Que la eficacia del individuo se incorpore al proceso continuo del devenir del mundo con arreglo a leyes [causales] no excluye que él, como uno de los factores de este proceso, simultáneamente signifique algo para sí mismo"13. En terminología más moderna, ello significa lo siguiente: la plausibilidad de una adscripción de autonomía agencial capaz de sustentar un juicio de atribución de culpabilidad personal depende esencialmente de que el comportamiento del agente pueda ser interpretado como expresivo -y potencialmente: re-definitorio- de su propia identidad, en la medida en que lo que ese agente hace o deja de hacer pueda ser racionalizado como la realización de un sistema de preferencias que son constitutivas de quién es contingentemente- ese agente, esto es: de su carácter. Rectificado de este modo, el hallazgo de Engisch en cuanto a la dimensión caracteriológica de una comprensión de la autonomía agencial no amenazada por la verdad del determinismo, me parece, es portador de una valía indesmentible.

Lo anterior es nada más que una muestra de la manera en que el libro Figuras y pensamientos del Derecho penal contemporáneo nos interpela a reabrir nuestro diálogo, el más fecundo de todos, con las poderosas mentes que nos precedieron en la cimentación de

\footnotetext{
${ }^{11}$ BELING, Ernst, Die Vergeltungsidee und ihre Bedeutung für das Strafrecht, Léipzig: Wilhelm Engelmann, 1908, p. 54.

${ }^{12}$ BELING, Die Vergeltungsidee, cit. nota ${ }^{\circ} 11$, p. 56.

${ }^{13}$ MERKEL, Adolf, Vergeltungsidee und Zweckgedanke im Strafrecht, Estrasburgo: Karl J. Trübner, 1892, p. 58.
} 


\section{MAÑALICH, Juan Pablo, “Recensión: GUZMÁN DÁLBORA, José Luis, Figuras y pensamientos del Derecho penal contemporáneo. Montevideo y Buenos Aires: Editorial BdF, 2014, xiv + 250 páginas.”}

esta compleja tradición que conocemos como la moderna dogmática jurídico-penal. Pero desde este punto de vista, el título no deja de ser perturbador. Guzmán Dalbora nos deja saber, ya en la portada del libro, que éste se ocupa de figuras y pensamientos del derecho penal contemporáneo. ¿Es ésta una sugerencia mínimamente plausible desde la perspectiva de lo que podríamos llamar la sociología descriptiva de nuestra -que no se les olvide: atroz- disciplina? ¿Se mostraría inclinada la generalidad de nuestros colegas a pensar en Birbaum, Radbruch, Mayer y Engisch como figuras del derecho penal contemporáneo? El hecho de que Guzmán Dalbora así lo sugiera es indicativo de aquella actitud intelectual que yo intentaba desentrañar al comienzo: una actitud de resistencia, que ahora se nos presenta referida a la frivolidad con la que habitualmente parecemos trazar la disposición cronológica del desarrollo de la ciencia del derecho penal.

Si se me permite extremar el argumento, y para concluir, diría que el libro de Guzmán Dalbora parece estar compuesto desde una cierta insatisfacción con nuestra situación histórico-espiritual, en lo que al cultivo de nuestra disciplina se refiere. En mi caso, su lectura me ha evocado la primera versión del prólogo que Ludwig Wittgenstein preparó como prólogo para sus póstumamente publicadas Investigaciones Filosóficas, que en definitiva apareció considerablemente recortado. Así rezaba el prólogo, bajo su constitución original:

"Este libro ha sido escrito para quienes se acercan amistosamente al espíritu con el que fue escrito. Creo que este espíritu es distinto al de la gran corriente de la civilización europea y americana. El espíritu de esta civilización, cuya expresión es la industria, la arquitectura, la música, el fascismo y el socialismo de nuestra época, es ajeno y antipático al autor. No es este un juicio de valor. No se trata de que crea que lo que hoy se presenta arquitectura lo sea, ni tampoco que no tenga una gran desconfianza ante lo que se llama música moderna (sin comprender su lenguaje), pero la desaparición de las artes no justifica un juicio desfavorable sobre una civilización. Pues las naturalezas auténticas y fuertes se desvían precisamente en esta época del terreno de las artes y se vuelven hacia otras cosas, y el valor del individuo se expresa de alguna manera. Desde luego, no como en la época de una gran cultura. Por así decirlo, la cultura es como una gran organización que señala su lugar a todo el que pertenece a ella, lugar en el que puede trabajar dentro del espíritu del todo, y su fuerza puede medirse justamente por su resultado en el sentido del todo. Pero en la época de la anticultura se hacen pedazos las fuerzas, y la fuerza del individuo es desaprovechada por las fuerzas opuestas y las resistencias. [...]

Para mí es muy claro que la desaparición de una cultura no significa la desaparición del valor humano, sino sólo la de algunos medios de expresión de este valor; con todo, siguen en pie el hecho de que veo sin simpatía la corriente de la civilización europea, sin comprensión por sus fines, en caso de que tenga algunos. Así pues, en verdad escribo para amigos diseminados por todos los rincones del mundo."14

En su prefacio al libro, Guzmán Dalbora nos deja entrever la actitud de resistencia que he intentado retratar para ustedes. Él nos dice que, a su juicio, traducir "es también una manera de investigar, por más que no disfrute del aprecio de los colegas más jóvenes ni se adecue a

\footnotetext{
${ }^{14}$ WITTGENSTEIN, Ludwig, Aforismos. Cultura y valor, Madrid: Espasa Calpe, 1995, pp. 38 ss.
} 
Polít. crim. Vol. 10, No 19 (Julio 2015), Rec. 2, pp. $398-408$.

[http://www.politicacriminal.cl/Vol_10/n_19/Vol10N19R2.pdf]

la producción en serie, esa por puntos, no de contrapuntos, en que se ha convertido actualmente la investigación universitaria" (pp. ix s.). Pero esa actitud de resistencia ciertamente no llega a ser una de resignación. Antes bien, y tal como se nos anuncia en ese mismo prefacio, los estudios que el autor del libro pone a nuestra disposición "pertenecen al entramado histórico-contemporáneo en que reposa aún lo medular de la doctrina del delito de nuestra cultura jurídica" (pp. x s.).

Por haber tenido a bien compartir los resultados de su erudita investigación en estos derroteros, genuinamente basales para nuestros emprendimientos intelectuales del presente, sepa usted, profesor Guzmán, que -para decirlo con Wittgenstein- sus amigos diseminados por todos los rincones del mundo le debemos infinita gratitud.

\section{REFERENCIAS BIBLIOGRÁFICAS}

BELING, Ernst, Die Vergeltungsidee und ihre Bedeutung für das Strafrecht, Léipzig: Wilhelm Engelmann, 1908.

BIERLING, Ernst Rudolf, Zur Kritik der juristischen Grundbegriffe, Gotha: Friedrich Andreas Berthes, 1887 y 1883.

, Juristische Prinzipienlehre, tomo I, Friburgo y Léipzig: J.C.B. Mohr (Paul Siebeck), 1894.

BINDING, Karl, Die Normen und ihre Übertretung, tomo I, 4ª ed., Léipzig: Felix Meixner, 1922.

BOCKELMANN, Paul, KAUFMANN, Arthur y KLUG, Ulrich, Festschrift für Karl Engisch zum 70. Geburtstag, Fráncfort del Meno: Vittorio Klostermann, 1969.

DUMMETT, Michael, Frege. Philosophy of Language, Nueva York: Harper \& Row, 1973.

EUCKART, Wolfgang, SELLIN, Volker y WOLGAST, Eike, Die Universität Heidelberg im Nationalsozialismus, Heidelberg: Springer, 2006.

KELSEN, Hans, Hauptprobleme der Staatsrechtslehre, Friburgo y Léipzig: J.C.B. Mohr (Paul Siebeck), 1911.

MAÑALICH, Juan Pablo, “Autonomía, determinismo y responsabilidad penal”, en: KINDHÄUSER, Urs y MAÑALICH, Juan Pablo, Pena y culpabilidad en el Estado democrático de derecho, Buenos Aires y Montevideo: BdF, pp. 181 ss.

, "Organización delictiva. Bases para su elaboración dogmática en el derecho penal chileno", Revista Chilena de Derecho, vol. 38, № 2 (2011), pp. 279 ss.

MERKEL, Adolf, Vergeltungsidee und Zweckgedanke im Strafrecht, Estrasburgo: Karl J. Trübner, 1892.

NAGLER, Johannes, "Der heutige Stand der Lehre von der Rechtswidrigkeit", en: BELING, Ernst et al.: Festschrift für Karl Binding zum 4. Juni 1911, Léipzig: Wilhelm Engelmann, 1911, tomo II, pp. 273 ss.

REMY, Steven, The Heidelberg Myth: The Nazification and Denazification of a German University, Boston: Harvard University Press, 2002.

WELZEL, Hans, Das deutsche Strafrecht, 10ª ed., Berlín: Walter de Gruyter, 1967.

WITTGENSTEIN, Ludwig, Aforismos. Cultura y valor, Madrid: Espasa Calpe, 1995. 